\title{
Analysis of Cultural Value and Protection Strategies of the Spatial Elements of Tibetan Historic Cities
}

\author{
Wei Wei ${ }^{1, a}$, Wan Bin ${ }^{2, b}$ \\ ${ }^{1}$ School of urban design, Wuhan University, China \\ ${ }^{2}$ School of urban design, Wuhan University, China

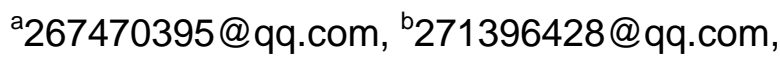 \\ MOE (Ministry of Education in China) Youth Fund Project of Humanities and Social Sciences
}

(Project No. 12YJC770059)

Keywords: Tibet; Historical and cultural city; Historical space; Heritage Protection

\begin{abstract}
This paper extracts boundary, partition, skyline and street space as four historical space elements of the three national historical and cultural city__Lhasa, Shigatse and Gyantse, and then analysis their ideological contents and cultural values which include the following contents_-boundaries that reflect ecological ethics and social ethics, partition expression changes of World View and street space reflects two aspects of World View. It analysis the situation of these space: "double core" intention is diluted, artificial skyline and vertical interface is damaged, old town's border intention is weakened and the shape and space texture of streets are damaged. Finally it proposes the following planning strategies: to protect "double core" structure overall, to control building height and establish "vertical purple line", to protect the landscape pattern and Circumanbulations on the peripheries and to protect traditional architectural patterns.

Tibet is an inhabited area of ethnic minority with a long history and unique culture, and the historical space elements of Tibetan central cities( symbolized by Lhasa, Shigatse and Gyantse) are very unique. Lhasa is the most representative cultural and the most abundant historical space; "Shigatse is the central city in Tsang Area, and it constitutes the center of politics and religion with Lhasa in the history of Tibet; Gyantse is a hub city which contacts Maekura Area and Tsang Area "[1]. The historical space of the three central cities is similar to each other, but totally different from other civilizations. According to the analysis of the historical space elements, this paper extracts the unique cultural value of the space elements of these three historical cities, and then puts forward the protection strategies based on the current situation of the space. (Fig.1)
\end{abstract}

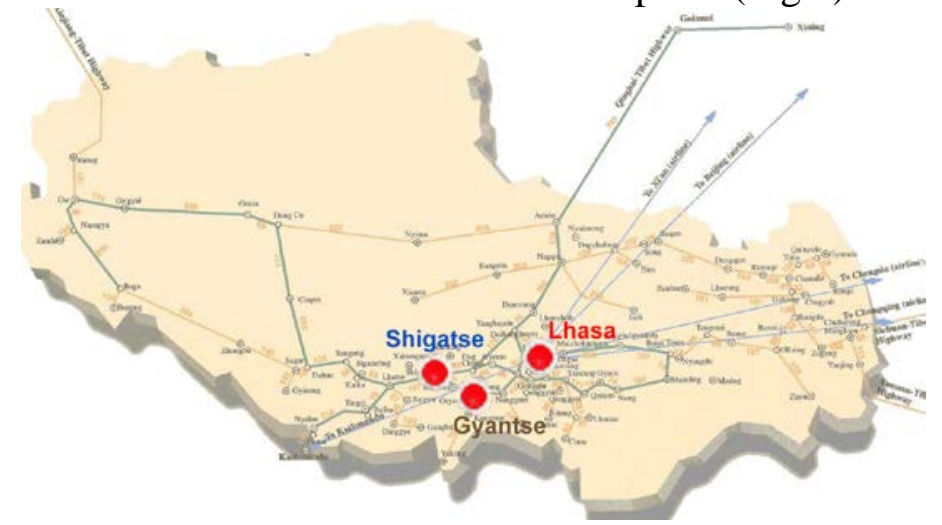

Fig. 1 Positions of Tibetan historic cities

The process of urban construction in Tibet area can be divided into the following 5 periods: “'Source' of construction(before Tubo Dynasty)_—_Boundaries' of construction(Tubo Dynasty)— 'Foreshadowing' of construction(Split period) ——_'Inheritance' of construction(periods of Sakya 、 Phagdru 、 Tsangpa Khan) — - 'Prosperity' of construction(dGavldan-pho-brang period),"[2]. DGavldan-pho-brang period(early 17th Century_— - the first half of 20th Century) is the key stage of urban development in Tibetan history and the spatial pattern of the three central cities is formed at this time. This paper is to select the historical space of this period as the research object. 
"Universal urban space elements in all of the human settlement patterns include urban boundaries, urban zoning, public places, urban streets, etc." ${ }^{[3]}$. Through the morphological combination of the urban elements, the space is endowed with cultural value, such as belief, institution, custom, psychology and so on. This paper selects 4 spatial elements__boundary, zoning patterns, skylines and streets as entry points to analysis the cultural value of Tibetan historic city space.

\section{Spatial elements of Tibet's historical cities}

\subsection{Urban Boundary}

Changes in spatial boundaries of Tibetan historic cities have experienced 4 stages:

Stage 1, Rdzaong Castle buildings on the Rdzaong Mountains constituted the main body of the cities and the defensive wall of the buildings was the boundary of the cities;

Stage 2, as the Rdzaong Castle buildings attracted people to live together, residential points were built up at the foot of Rdzaong Mountains. These residential points, which surrounded the Rdzaong Mountains centripetally, formed a vague definition of space. This vague definition, together with the mountain line where the residential points were built 、 the waters and the farmland around, formed an integral boundary intention by "mountain, water, fields";

Stages 3, with the popularization of Tibetan Buddhism, the Circumanbulation roads on the city outskirts became new city boundaries.

Stage 4, the defensive boundaries of Rdzaong Castle buildings, the Circumanbulation roads of temples and the spatial boundary intention outside together formed an urban boundary structure which is "a great circle contains two small ones". (Fig.2, 3, 4)

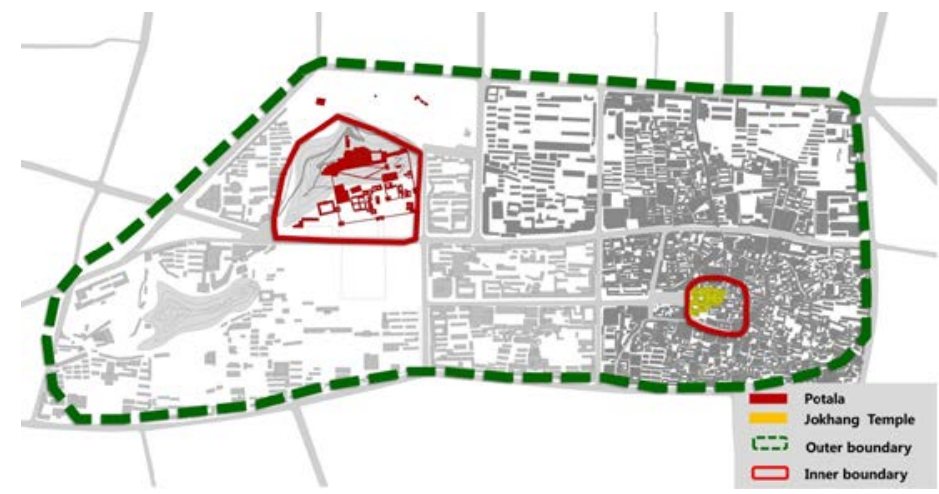

Fig. 2 Boundaries of Lhasa city

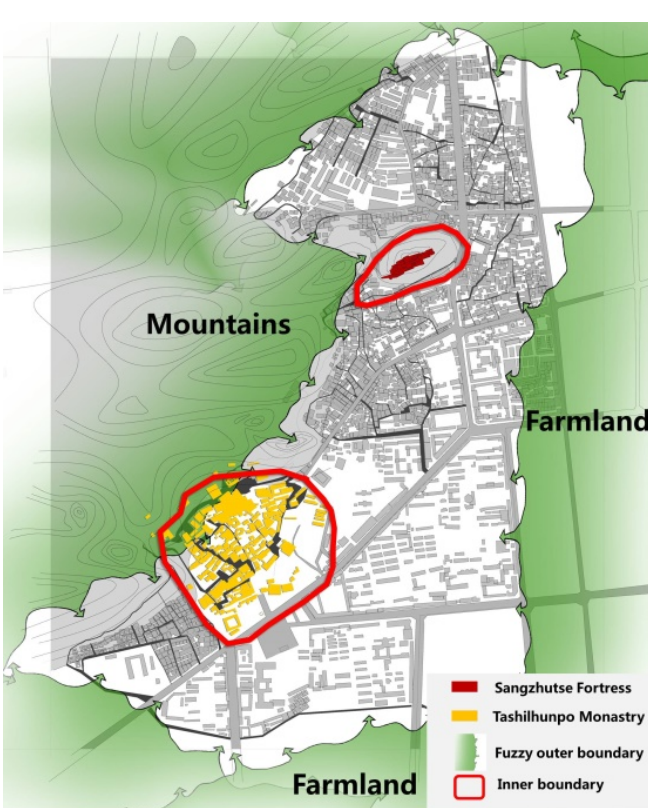

Fig.3 Boundaries of Gyantse

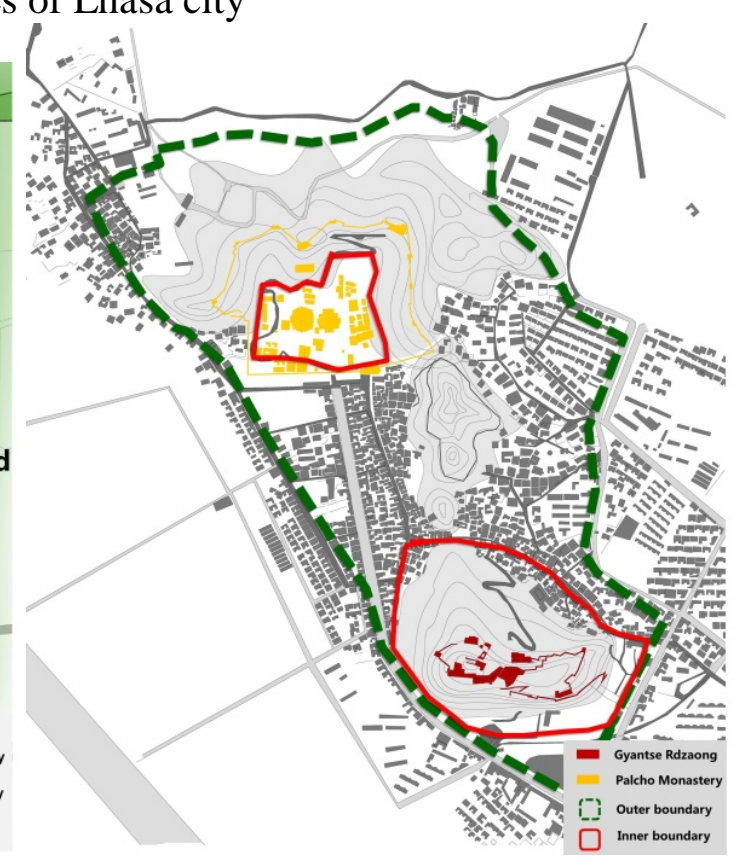

Fig. 4 Boundaries of Shigatse 


\subsection{Urban Zoning}

The most typical historical space partition in Tibetan historic cities is the Rdzaong Mountains-centered Administrative Region and the temple-centered Religious Region. These two unique partitions form together and determine the unique style of urban spatial morphology layout.

\subsubsection{Administrative Region—_ Rdzaong Mountains, the ruling center}

The word "Rdzaong" is the Tibetan transliteration, the meaning is "Bunker" and "Castle". In the period of Tubo Dynasty or even earlier time, Rdzaong Castle settlements built on the mountains were the main origin of the cities. More formal Rdzaong Castles started to be built during the Phagdru Regime in 14th century. And they had played the role of ruling structure till the mid-20th century. Rdzaong Mountains were the core of the cities, and residents gathered centripetally under the jurisdiction and protection scope of the Rdzaong Mountains-this phenomenon laid the spatial pattern of the whole city. And Rdzaong Mountains became the center of the city plane patterning and have stayed stable ever since. Potala in Lhasa、Sangzhutse Fortress in Shigatse and Gyantse Rdzaong in Gyantse are all the centers of their respective cities. (Fig. 5, 6, 7)

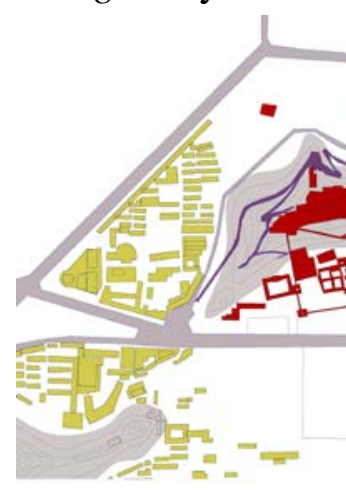

Fig. 5 Potala Palace area in Lhasa

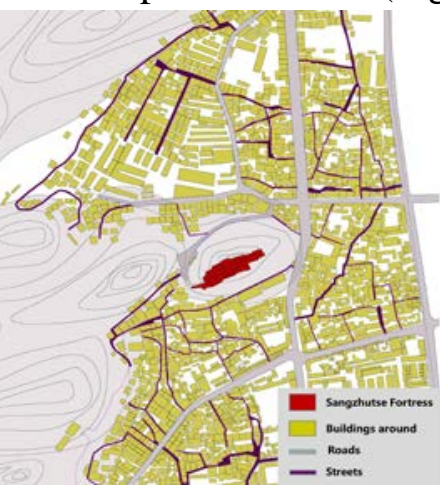

Fig. 6 Sangzhutse Fortress area in Shigatse

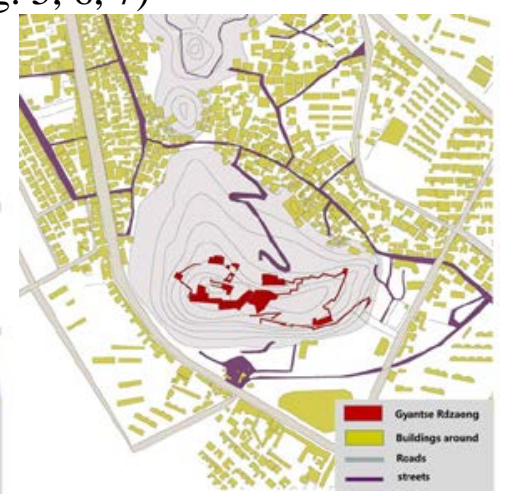

Fig. 7 Gyantse Rdzaong area in Gyantse

\subsubsection{Religious Region-Temples, the spiritual center}

Tibetan Buddhism is rooted in Tibetan Bon Religion, Indian Buddhism and Chinese Buddhism, and it was officially established in the 11th-12th Century. In the mid-17th century Tibetan Buddhism established a Political system_—Integration of Religion and Politics. As a result, Tibetan Buddhism temples became the sacred space of central cities. Reverence and awe of religion made temples the "core" of plane pattern or the "top" of facade pattern. For example, the plane pattern of Lhasa is a concentric cored by Jokhang Temple; Shigatse, cored by Tashilhunpo Monastery, and Gyantse, cored by Palcho Monastery, respectively, make themselves a fan-shaped Plane pattern and a temple—vertex facade pattern(Fig.8, 9, 10).

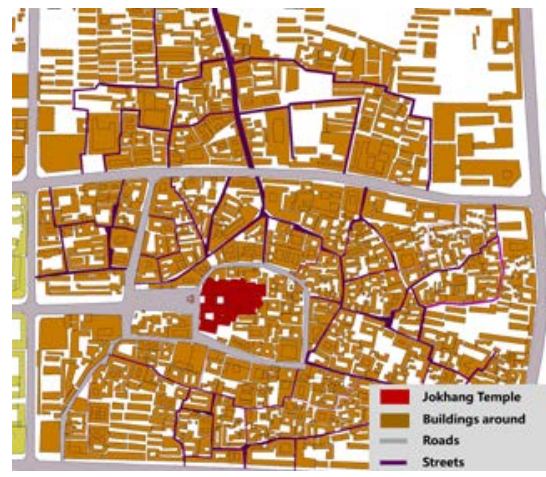

Fig.8 Jokhang Temple area in Lhasa

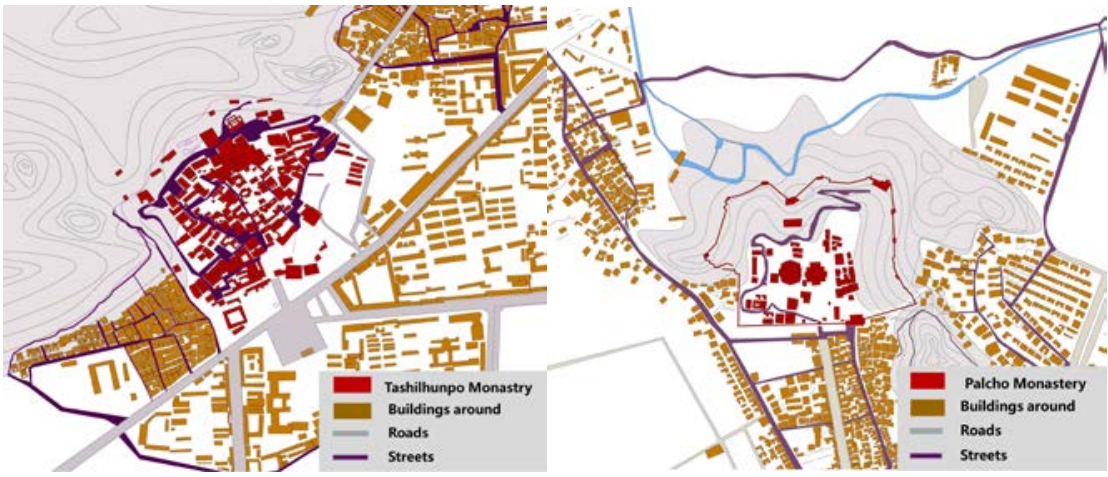

Fig.9 Tashilhunpo Monastry area in Shigatse
Fig.10 Palcho Monastery area in Gyantse 


\subsection{3 “Double cores" Planar spatial Form_—Double Concentric Circles}

In theocratic Ganden Phodrang period, the planar spatial form of Tibetan central cities was stable as "Double Concentric Circles" cored by Rdzaong Mountains and Temples. Rdzaong Mountains dominate the urban form with its body mass, height and defense facilities; Temples, then, agglomerate core functions of the city by its spiritual cohesion, and dominate all space elements of the cities by its own elements like color(resplendent and magnificent)、roof(rich and varied)、 architectural form(versatile) and so on. The two centers are relatively independent but also supplementary to each other, which reflect the close relationship between urban rule and religious power, secular life and spiritual beliefs.(Fig.11、12、13)

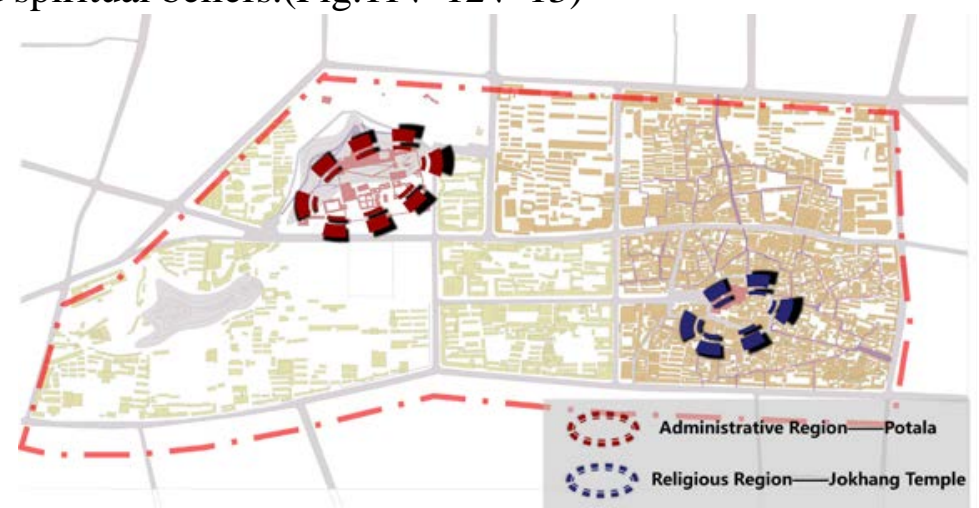

Fig.11 "Double cores" space form in Lhasa

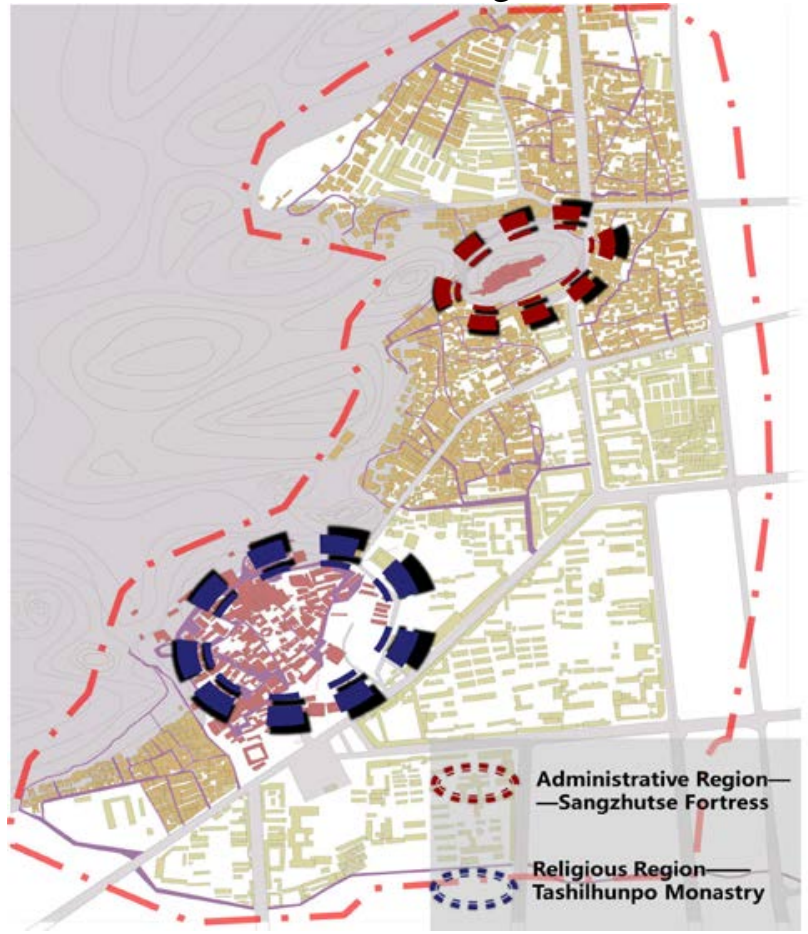

Fig.12 "Double cores" space form in Shigatse

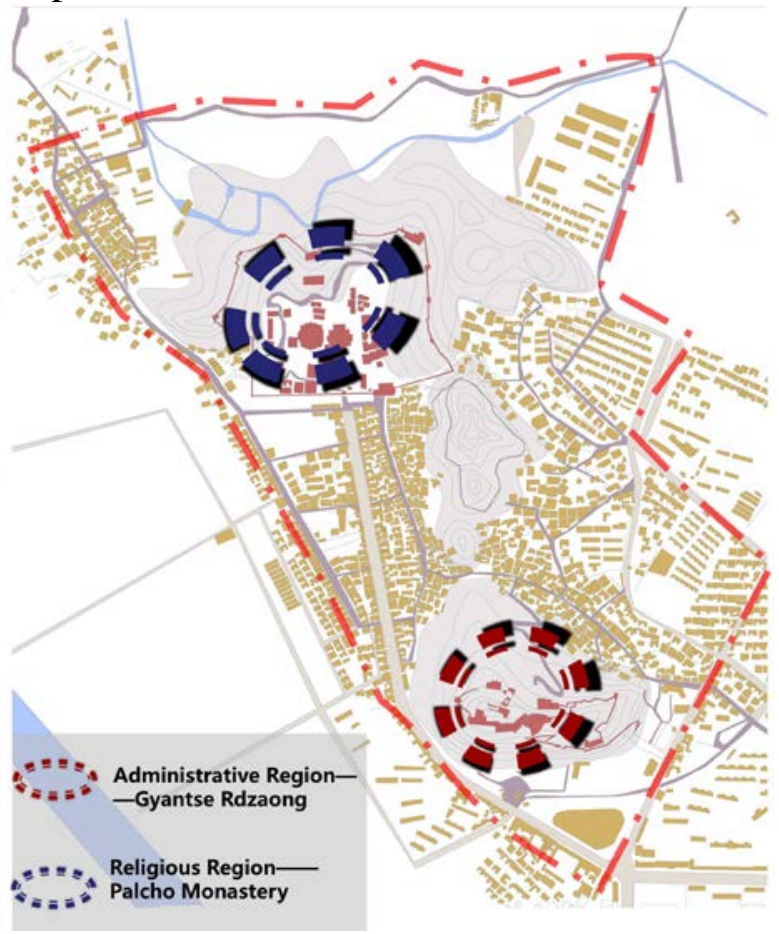

Fig.13 "Double cores" space form in Gyants

\subsection{4 “Double cores” Vertical spatial Form_—City skyline like a “Continuous M"}

"Double cores” pattern is not only reflected in the city's plane form, but also reflected in the city's facade space. Rdzaong Mountain buildings and temples are located on two mountains seperately, and the business district and residential area locate in the gentle slope or plain region. Along the city's strip shape, with the mountains in the distance as the background, the city shows the undulant and beautiful city skyline which looks like a "continuous M".(Fig.14、15、16) 


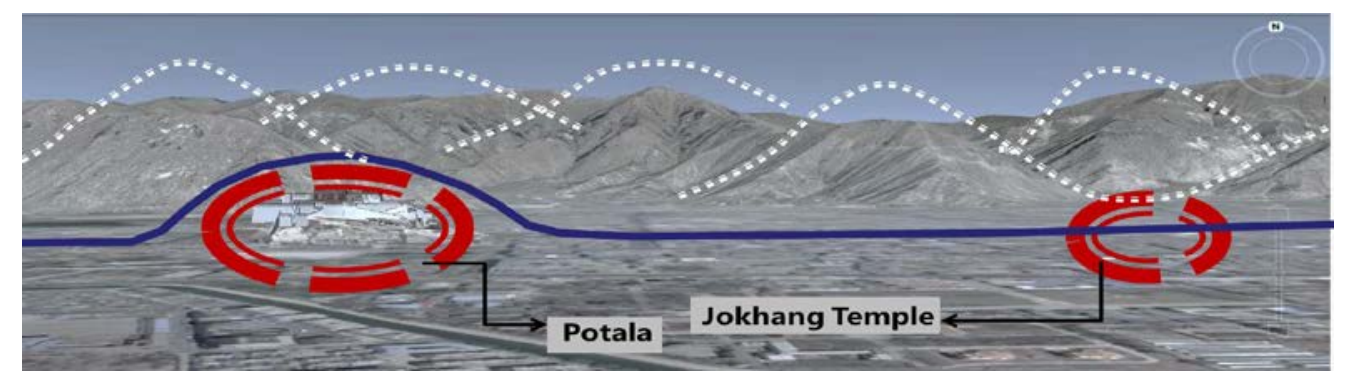

Fig.14 Historical space skyline in Lhasa

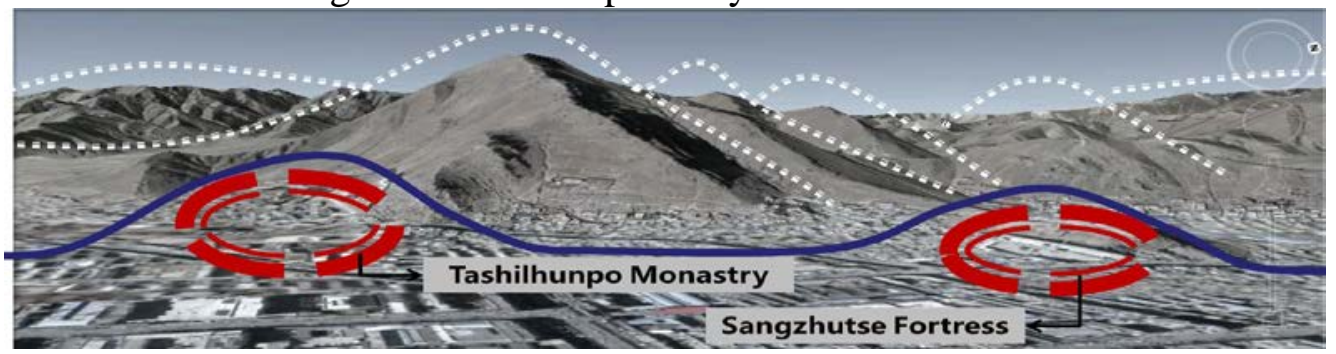

Fig.15 Historical space skyline in Shigatse

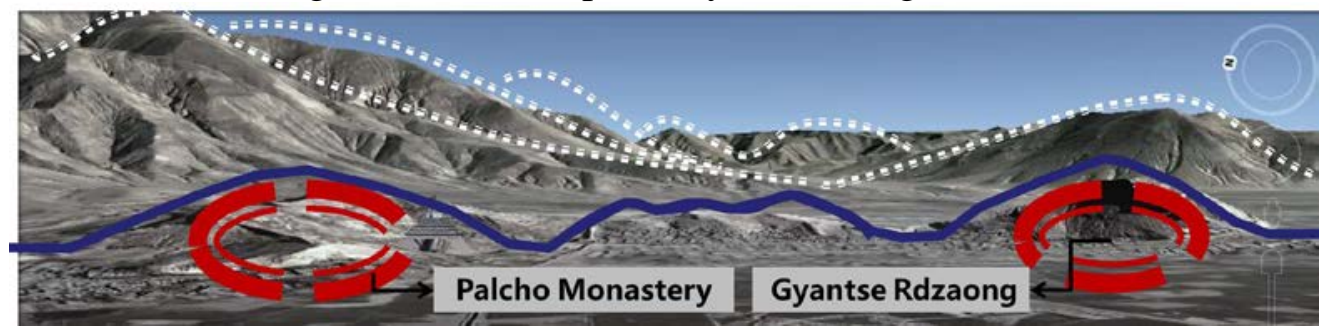

Fig.16 Historical space skyline in Gyantse

\subsection{Urban Streets}

This paper analyzes the spatial elements of the streets in Tibetan historical cities from two aspects, one is the streets as urban form, another is the streets as a place where urban public activities happen.

\subsubsection{Streets as urban form_—Reticular pattern, free and lively streets}

The Tibetan central cities is a "double concentric circle-shaped” strip city. As the city's skeleton, streets are reinforcing with cities and develop a reticular pattern combined with terrain. Under the influence of Tibetan Buddhism, in Tibet, "motions associated with Tibetan Ceremonial Buildings are circular” ${ }^{[4]}$. The space organization of the circular trajectory runs through the whole street space. As a result, streets in Tibet show an organic form and pleasant scale, which, combined with the architecture, develop plentiful and varied public space. These space makes streets full of vitality and brings mysterious and active space experience.(Fig.17、18)
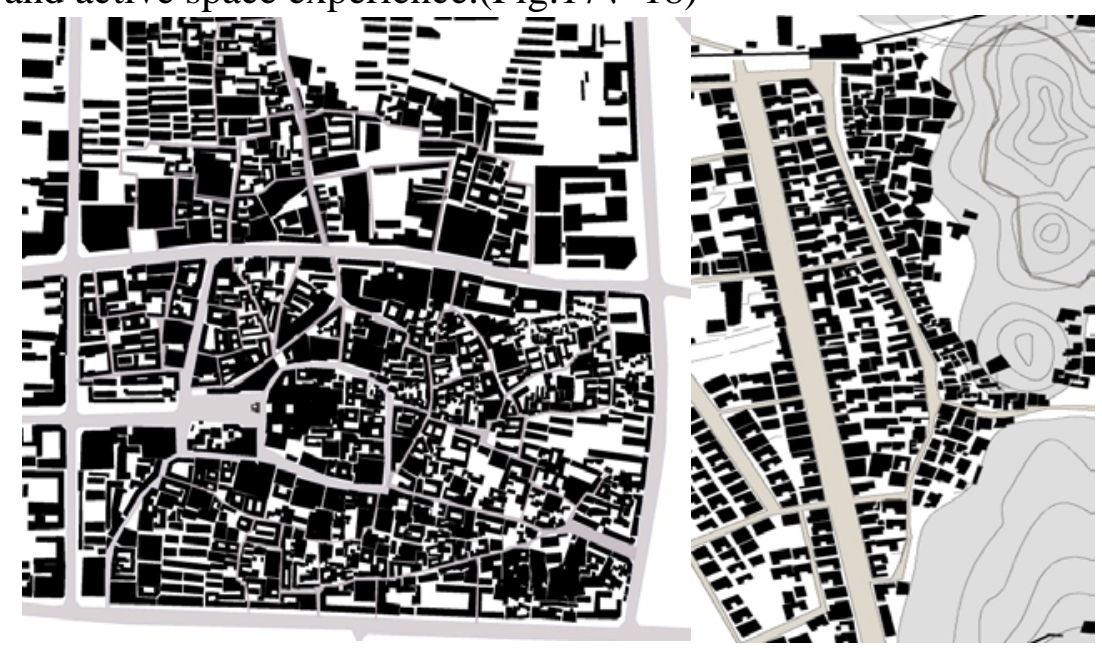

Fig.17 Space texture of Barkhor Street in Lhasa

Fig.18 Space texture of Jiarijiao Street in Gyantse 


\subsection{2 streets as a place where urban public activities happen-Space Contact, demands}

\section{of religious Activities}

As the bearer of public activities, the streets reflect their economic value and social significance: transportation, business activities and social activities, etc. In Tibet, streets, not only provide plentiful social and communication space, but also provide a complete set of spatial logic for the Tibetans' daily activities. In addition, Tibetans have their own unique and pious way of worship such as Circumanbulating, circling around the mountain and Kowtow, etc. And as the bearing space of these Buddha-worship activities, streets in Tibet develop unique Circumanbulations and form unique street space landscape full of Tibetan characteristics.

\section{The cultural value of spatial elements of Tibet's historical cities}

The analysis of specific cultural values can be started from the perspective of the universe, ethics, and society, that is, the Tibetan people's understanding formed in their long history about the world, themselves and others. From the existing spatial elements in Tibet historical city, many of the unique and rich cultural value of Tibetan nationality can be digged out.

\subsection{Cultural value of Urban Boundary_ecological ethics and social ethics}

The essence of the boundary is the distinction and definition of people, which reflects the unity inside and the independence outside. The historical boundary of Tibetan cities reflects the ecological notion and social structures Tibetans formed in the long history.

Stage1_-defensive walls of the Rdzaong Mountains buildings ,which separated rulers and the people with a tough stance, reflect the strict hierarchy of ancient Tibetan society.

Stage2_ — the integral boundary intention of "mountain, water, fields" reflects the natural integration between urban and rural areas and embodies the Tibetan ecological ethics to cherish nature and to live in harmony with nature.

Stage3 、 4-the long circular Circumanbulations, as the urban boundary, and Circumanbulations inside the cities, as the definition of Rdzaong Mountains and Temples, highlight that the Tibetan social ethics is based on Tibetan Buddhism.

\subsection{Cultural value of Urban Zoning__ changes of the World View: "Mandala")", "trayo dhätava"}

Changes in urban zoning essentially reflect the Tibetan ultimate ideal of the relationship between man and god, which means the World View.

In the spatial pattern of early Tibetan city, rulers occupied the peak of the mountain and people prostrated at the foot of rulers, which embodies the Tibetan nature worship to mountains and stone. With the advent of the temple as another center of the city, it's indicated that the boundaries of "heaven" and "human world" is gradually clear, and the Tibetan original World View begin to merge with Tibetan Buddhism Buddhist doctrines. As to the Ganden phodrang period, secular rule and religious rule were mixed together. They were no longer independent of each other, but integrated with each other in the spatial relations, which developed a stable "double cores" space pattern. These show the unique change course of World View which experiences the "Consolidation—_-divided_Consolidation" process in relationship between "God" and "human". The "double cores" space pattern highlights the center, stresses the main statue, pay attention to primary and secondary, which secretly meets the essence of "Mandala cosmology". That is, the physical space within the city and the Tibetan cosmic order are echoed and integrated to achieve the concept of universe in their religion.

Moreover, the vertical space of the city skyline corresponds to Tibetan Buddhism's "trayo dhātava". Residential space located in the lowest is the first level, a symbol of "desire realm ". Rdzaong Mountains and Temples built on the mountains are the second level, a symbol of "form realm ". The top of temples and the highest Rdzaong Mountain buildings are the third levels, a symbol of "formless realm ". The undulating and layering of the city skyline are a symbol of gap and distance in "trayo dhātava".

\subsection{Cultural value of Urban Zoning — the other two aspects of World View}

In addition to the answer to "relationship between man and God", the World View has a number of other important propositions: where do people come from, and where to go? What is the ideal world 
like in people's imagination? The form of the city streets in Tibet contains the answers to these propositions. Tibetans believe the conception of "Samsara in the Six Realms". That is the" three good way"___ods, asuras or demigods, human beings, and the "three evil way"_-hells, animals, hungry ghosts. And people are all samsaric in the Six Realms generation after generation. Everyone should be compliant in order to get the happiness of the next life and to reincarnate in the" three good way". Suffering in this life is not to fall into the" three evil way" in the next life. As the basic skeleton of the city, most streets In Tibetan cities are circular. Tibetans walk around on the circular roads in the clockwise direction to seek a kind of expectation to reincarnate in the" three good way". The way of praying across the circular Circumanbulations again and again, directly reflects the "Samsara" thought in Tibetan Buddhism. Another significance of Tibetan city streets are to draw the outline of the ideal world —-"Mandala". For example, the Barkhor Street Historic District's space structure, which takes Jokhang Temple and the Jokhang Circumanbulation as its center, forms three concentric circles. All buildings are facing the Jokhang Temple. "The three concentric circles-like Circumanbulations and the plane layout of Jokhang Temple are somewhere confirms the Tibetan Esoteric Buddhism thought_—_Mandala','5]. And they show the relationship between primary and secondary in the universe and the close association of all things.

\section{Historical space status and planning strategies}

The cultures above are unique in the Chinese civilization, and they are precious spiritual wealth of the Tibetan historical civilization. As a heritage to bear and embody these cultural values, the space elements contain Tibetan unique traditional world view and ecological ethics. They should be fully protected.

\subsection{Analysis on current situation of historical factors}

Before the protection of historical cities, ” First ,we should seek the spirit of our city, and its historical essence and its continuous life. Only in this way can we identify and explore the character and the collective soul of the city in a certain way" ${ }^{[6]}$. But the current situation of historical elements is not optimistic.

The Status quo problems of the historical space of the Tibetan historic city are concentrated in the following four aspects:

(1)"Double cores" intention is diluted and the overall pattern of historical space is destroyed. With the rapid expansion of urban space, the supreme status of "double cores" is challenged and its space dominance declines. "Double cores" intention is gradually diluted, and change to the "single core" or "multi centers".

(2) The contour of urban natural skyline is well preserved. But the artificial horizon and the vertical interface are tended to be damaged by the height and shape of the modern buildings. The" M-shaped" city skyline is formed by means of mountain terrain, which is relatively stable, and therefore better preserved. But a large number of non-protected traditional buildings inside the old cities were removed, replaced by modern architecture. Surrounding buildings of the old cities are also in a modern style. These are extremely disruptive to the traditional vertical interface of the old cities.

(3) The old city's boundary intention is weakened, and even wiped out. The original "mountain, water, field" boundary intention of the Tibetan central cities is relatively vague, and it is extremely easy to be destroyed. With the development of city and the rapid expansion of space, the original boundary intention of the old cities space is weakened. Many circumanbulations have been destroyed. Many boundary intentions have died out.

(4) A part of the historic districts of the old cities is destroyed. The morphology of streets and spatial texture are destroyed seriously. Traditional morphology of streets is irreversibly damaged with removal to the traditional construction. Crossing of modern urban road makes the original continuous and interesting streets texture lost its mysterious and vivid space experience.

\subsection{Planning strategies}

In view of the severe situation, this paper puts forward the following protective measures: 


\subsubsection{The overall protection of the "two poles" pattern in order to strengthen the urban form mark.}

The protection of the old city should focus on maintaining the overall spatial pattern of the old city. Protection thoughts change from "point - line" to "surface - body". Use the planning to guide and strengthen the city's "double cores" spatial pattern.

3.2.2 The overall control of building height, the formulation of “vertical purple line "to protect "the continuous $M$ type" skyline.

Control the overall building height to the whole city and highlight the city's "M" - type skyline, to ensure that the commanding heights of the city space in the entire city are the Rdzaong Mountains and the temple. Combined with the actual situation of Tibetan cities, the content of "vertical purple line control" should be added to the establishment of conservation planning of historical cities.

3.2.3 To protect the ecological pattern of the old city and the surrounding circumanbulation to maintain the old cities boundary intention.

Expand the scope of the protection of the old city appropriately, make sure the old city is in the core area of the protection of the core area. Protect the landscape ecological pattern of the city. The circumanbulation outside the old city should be maintained and strengthened. Focus on the protection of the sacred and religious landscape along the road.

\subsubsection{Protection of the building structure of residents of the old city in to maintain the} cultural experience of street space.

Focus on the protection of existing traditional streets, not only should we protect their street landscape, but also ensure their traditional living functions. The buildings of residents in the old city is the base of the whole city, only by taking the basement as a reference can we have the texture of the city streets. As old buildings implicate Tibetan life, religious psychology and a large number of historical information, we should protect this layer of the existing space base, in order to maintain good street space experience.

\section{Conclusion}

The spatial elements of the Tibetan central cities contain a lot of thoughts and connotations. It is these thoughts and connotations that endow them the spiritual value of the Tibet urban space, which is more important than the value of the material themselves. Only by preserving the elements of the space can the traditional thoughts and culture of Tibet get a substantial carrier, and valuable historical wealth will not be lost in the tide of modernization.

\section{References}

[1] Wei Wei,Li Boxun,Jiao Yongli. Research on the evolution and pattern of Tibetan central cities[J]. Architectural Journal.2007.(7): p. 81-82

[2] Wei Wei. Construction of Tibetan Settlements[D]. Wuhan University.2008: p. 1-2

[3] (America)Kostof, Spiro; Castillo, Greg. The City Assembled: The Elements of Urban Form Through History[M]. Beijing: China Architecture \& Building Press. 2008 : p.6

[4] (Norway)Knud Larsen. The historical map of Lhasa City: traditional Tibet architecture and city landscape[M]. Beijing: China Architecture \& Building Press.2005: p.43

[5] Wei Wei. Appreciation of the ancient city of Lhasa[J].China construction.2007.(4): p.56

[6] (America)Spiro Kostof, Richard Tobias. The City Shaped: Urban Patterns and Meanings Through History[M]. Beijing: China Architecture \& Building Press.2005:p.86

\section{Annotations}

1) Mandala: Its original meaning is the altar of the gods. Its layout reflects the Tibetan Buddhist Tantric view of the universe, and it is a kind of cognitive structure of the world. The settlement pattern of Mandala ,arranged in the standard orientation, superimposes the order of the universe on the 
man-made space to realize the concept of small universe in Hinduism. The small universe can protect the peace and security of the settlement. This idea has been widely used with the spreading of India Buddhism into Tibet. 